\title{
The National Kidney Foundation of Illinois KidneyMobile: a mobile resource for community based screenings of chronic kidney disease and its risk factors
}

Swati Lederer ${ }^{1,2,3,4^{*}}$, Laurie Ruggiero ${ }^{6,7}$, Nicole M. Sisen ${ }^{5}$, Nancy Lepain ${ }^{5}$, Kate Grubbs O'Connor ${ }^{5}$, Yamin Wang ${ }^{6}$, Jinsong Chen ${ }^{3}$, James P. Lash ${ }^{3}$ and Michael J. Fischer ${ }^{1,2,3}$

\begin{abstract}
Background: Early detection and treatment of chronic kidney disease (CKD) and its risk factors improves outcomes; however, many high-risk individuals lack access to healthcare. The National Kidney Foundation of Illinois (NKFI) developed the KidneyMobile (KM) to conduct community-based screenings, provide disease education, and facilitate follow-up appointments for diabetes, hypertension, and CKD.

Methods: Cross-sectional design. Adults $>=18$ years of age participated in NKFI KM screenings across Illinois between 2005 and 2011. Sociodemographic and medical history were self-reported using structured interviews; laboratory data and blood pressure were assessed using standard procedures.

Results: Among 20,770 participants, mean age was 53.5 years, 68\% were female, 49\% were African-American or Hispanic, 21\% primarily spoke Spanish, and at least 27\% lacked health insurance. Seventy-eight percent of participants with elevated blood pressure ( $\geq 140 / 90 \mathrm{mmHg}$ ) were aware of having hypertension, $93 \%$ of participants with abnormal blood glucose (fasting glucose $>126 \mathrm{mg} / \mathrm{dl}$ or a random glucose of $>200 \mathrm{mg} / \mathrm{dL}$ ) were aware of having diabetes, and $19 \%$ of participants with albuminuria (> $30 \mathrm{mg} / \mathrm{gm}$ ) were aware of having CKD. In participants reporting hypertension, $47 \%$ had blood pressure $\geq 140 / 90 \mathrm{mmHg}$, and in those reporting diabetes, 56\% had blood glucose $\geq 130 \mathrm{mg} / \mathrm{dl}$ (fasting) or $\geq 180 \mathrm{mg} / \mathrm{dl}$ (random). Among 4937 participants with abnormal screening findings that participated in follow-up interviews, 69\% reported having further medical evaluation.

Conclusions: A high-risk disadvantaged population is being reached by the NKFI KidneyMobile and connected with healthcare services. A significant proportion of participants were newly informed of having abnormal results suggestive of diabetes, hypertension, and/or CKD or that their diabetes and hypertension were inadequately controlled.
\end{abstract}

Keywords: Kidney disease, Diabetes, Hypertension, Screening, Awareness

\section{Background}

Chronic kidney disease (CKD) is a common and costly disease affecting approximately $14 \%$ of the adult population in the United States and accounting for approximately 20\% of Medicare Part A and B costs [1]. Despite the significant utilization of healthcare services among

\footnotetext{
* Correspondence: swati.lederer@va.gov

${ }^{1}$ Center of Innovation for Complex Chronic Healthcare, Jesse Brown VA Medical Center, Chicago, IL, USA

${ }^{2}$ Edward Hines Jr. VA Hospital, Hines, IL, USA

Full list of author information is available at the end of the article
}

this patient population, CKD continues to be strongly associated with poorer patient outcomes including an increased risk of death, cardiovascular events, end-stage kidney disease (ESKD), and hospitalizations $[1,2]$.

Large screening initiatives such as the National Health and Nutrition Examination Survey (NHANES) and the Kidney Early Evaluation Program (KEEP) have found that most adults afflicted with CKD are unaware of their diagnosis [3-5]. Furthermore, awareness of comorbid conditions that increase risk of CKD, such as diabetes and hypertension, is also suboptimal. The under-recognition

(c) The Author(s). 2018 Open Access This article is distributed under the terms of the Creative Commons Attribution 4.0 International License (http://creativecommons.org/licenses/by/4.0/), which permits unrestricted use, distribution, and 
and delayed treatment of CKD and its associated health problems hastens disease progression and contributes to the growth of the ESKD population [3, 5-10]. Studies also show that low socio-economic subgroups, African Americans, and Hispanics have lower disease awareness and carry a higher burden of ESKD compared to the general population [11-13]. These vulnerable populations may have barriers to accessing healthcare resulting in later diagnoses of medical conditions [11-14]. Improving awareness of CKD and its comorbid conditions allows patients to seek the appropriate medical management, obtain fundamental disease knowledge, and participate in disease management.

Mobile screening initiatives have been successful in identifying individuals who may not otherwise seek medical care and facilitating the early diagnosis of silent diseases (e.g., CKD, hypertension, diabetes, and breast cancer) [15-19]. While findings from broad screening initiatives for hypertension, diabetes, and kidney disease are well-known, community-based mobile screening programs targeting under-insured individuals without access to primary care providers have not been well characterized. In addition to facilitating early diagnoses, these initiatives often provide individuals with health education and primary care follow up. Community-based screening initiatives also help educate public health officials and health providers about the burden of disease within specific communities and may inform the development and implementation of targeted interventions.

The National Kidney Foundation of Illinois (NKFI) developed a KidneyMobile (KM) as a mobile screening vehicle in 2005 to enhance the detection of hypertension, diabetes, and kidney disease in high-risk and vulnerable communities across Illinois. Working with community partners, the NKFI KM has conducted almost 41,000 screenings for diabetes, hypertension, and kidney disease in underserved areas between the years of 2005-2014. The KM also provides interactive educational activities and facilitates healthcare provider follow up for participants with abnormal screening results who lack access to healthcare services. To characterize the population reached by screenings and to evaluate the impact of this program, we examined data collected from 20,770 participating individuals between the years of 2005-2011.

\section{Methods}

\section{Study sample and design}

We conducted a cross-sectional analysis of data from NKFI KM participants throughout Illinois between 2005 and 2011. A total of 23,166 adult participants over the age of 18 were voluntarily screened. The NKFI KM was developed to conduct free screenings, provide disease education (diabetes, hypertension, CKD), and facilitate healthcare appointments for participants. The NKFI partnered with federally qualified health centers, health departments, and community hospitals in underserved areas to ensure that we targeted a high-risk population, characterized by substantial proportions of underinsured as well as uninsured adults without ready access to health care. Examples of such high-risk groups in our screenings included urban communities with significant percentages of African American and Hispanic adults subject to health disparities and rural communities with geographic barriers to health care services. Additionally, screening sites were selected based on their ability to provide resources for the screening day (e.g., volunteers, space, equipment) and post-screening follow up care.

A screening visit consisted of three stages and was led by a nurse who was assisted by trained healthcare volunteers. First, sociodemographic information, medical history, vital signs, anthropometric measures, and laboratory tests were obtained from participants. Second, educational information related to healthy living, hypertension, diabetes, and CKD was provided to participants. Third, participants with abnormal screening results met individually with a healthcare provider for further consultation. Those participants who had health insurance were directed back to their primary care provider, while those participants without health insurance were provided with a healthcare referral for a follow up appointment at a federally qualified health center or community hospital. Finally, attempts were made to reach participants with abnormal screening tests, by telephone for follow up to ensure that they had visited a healthcare provider following screening.

IRB approval from the University of Illinois at Chicago was obtained for analysis of these screening data, which had originally been obtained for non-research purposes.

\section{Variables and data sources}

Sociodemographic characteristics were self-reported by participants on a 19-item questionnaire at the initial screening visit. These characteristics included age, sex, race/ethnicity (white, African-American, Hispanic, Asian/Pacific Islander, other), primary language (English, Spanish, other), presence of health insurance and primary provider, and personal or family history of hypertension, diabetes, kidney disease. Height, weight, and manual blood pressure were measured by a trained nurse per standard protocols [20]. If the systolic blood pressure was greater than $160 \mathrm{mmHg}$, the reading was repeated. Blood glucose measurements were drawn and analyzed via the One Touch Ultra-2 device [21]. After collecting a clean catch midstream urine sample from all participants, a urine dipstick and a urine microalbumin were analyzed onsite by Clinitek device [22]. Any participant with albuminuria (defined below), personal history of diabetes, or an abnormal serum glucose testing was 
offered a blood test to measure serum creatinine, either on site by the Abbott I-stat Chem $8+$ or by a nearby hospital laboratory [23].

\section{Definition of variables}

We defined prevalent hypertension as participants who self-reported a history of hypertension, or those who had a systolic blood pressure $\geq 140 \mathrm{mmHg}$ or a diastolic pressure $\geq 90 \mathrm{mmHg}$, while recognizing that a definitive diagnosis of hypertension cannot be made by a single blood pressure measurement. Among those participants with prevalent hypertension, awareness of hypertension was defined as an affirmative to the following questionnaire item: "Have you ever been told you have high blood pressure or hypertension?". Among participants who reported a history of hypertension, control of the disease was defined as having both a systolic blood pressure of $<140 \mathrm{mmHg}$ and a diastolic blood pressure of $<90 \mathrm{mmHg}$.

We defined prevalent diabetes as participants who self-reported a history of diabetes, a fasting serum glucose $\geq 126 \mathrm{mg} / \mathrm{dl}$ or a non-fasting glucose $\geq 200 \mathrm{mg} / \mathrm{dl}$, recognizing that a definitive diagnosis of diabetes cannot be made by a single blood glucose measurement and requires confirmatory testing [24]. Among participants with prevalent diabetes, awareness of diabetes was defined as an affirmative to the following questionnaire item: "Have you ever been told that you have diabetes or high blood sugar?". Among those participants reporting a history of diabetes, control of the disease was defined as a fasting blood glucose of $<130 \mathrm{mg} / \mathrm{dl}$ or a non-fasting blood glucose of $<180 \mathrm{mg} / \mathrm{dl}$ [24].

We defined prevalent chronic kidney disease as participants self-reporting a history of kidney disease or those with a urine albumin to creatinine ratio of $\geq 30 \mathrm{mg} / \mathrm{gm}$, recognizing that diagnosis of kidney disease cannot be made by a single urine measurement [25]. Among those with prevalent CKD, awareness of the condition was defined as an affirmative to the following questionnaire item: "Have you ever been told you have kidney disease?"

A small subset of the total cohort underwent blood testing to measure serum creatinine. Among those participants, eGFR was calculated using the modification of diet in renal disease (MDRD) equation [26].

\section{Statistical analysis}

All sociodemographic, clinical and laboratory data from participants screened was organized into analytic datasets. Participant characteristics were summarized using means with standard error for continuous variables and frequency distribution with percentages for categorical variables. Characteristics were compared across strata of albuminuria by Chi-Squared or ANOVA testing as appropriate. Missing values occurred under the following circumstances: i) when a participant failed to answer a question on a reporting form, ii) when a physical measure was not obtained, iii) when a laboratory test was not performed. All statistical summaries were conducted using SAS, version 9.1 (Cary, NC, USA).

\section{Results}

Participant sociodemographic and clinical characteristics

Out of a total of 23,166 adults participating in KidneyMobile screenings across Illinois from 2005 to 2011, 20,770 had complete data regarding age, sex, and race/ ethnicity, and were included in the final analytic cohort. Figure 1 illustrates the geographic distribution of the KM screening across Illinois. Nearly half of the participants (54\%) were from the greater Chicago area, $44 \%$ were from the remainder of Illinois, and $2 \%$ were not known.

The mean age of participants was 53.5 years, approximately $68 \%$ were female, $58 \%$ were of non-White racial/ ethnic background, and 21\% reported Spanish as their primary language (Table 1). A large percentage of participants either lacked health insurance $(27 \%)$ or were unsure if they had active insurance (13\%), and 50\% did not have or did not know if they had a primary care provider. While $39 \%$ of participants reported a history of hypertension, $20 \%$ and only $5 \%$ of participants reported a history of diabetes mellitus and kidney disease, respectively. A family history of hypertension (54\%) and diabetes (43\%) were common among participants, but a family history of kidney disease was reported by only $12 \%$. Among all participants, 31\% were overweight (BMI 25-29.9), 29\% were obese (BMI 30-39.9), and 6\% were morbidly obese (BMI > 40). The mean systolic and diastolic blood pressure among participants was $127.5 \mathrm{mmHg}$ (se 0.13) and $76.6 \mathrm{mmHg}$ (se 0.08), respectively. Most participants (72\%) had fasting or non-fasting blood glucose levels within normal range.

Most participants (74\%) had no evidence of albuminuria, whereas $20 \%$ were found to have between 30 and $300 \mathrm{mg} / \mathrm{gm}$ of albuminuria and $1.5 \%$ were found to have $>300 \mathrm{mg} / \mathrm{gm}$ of albuminuria. Approximately $4 \%$ of screening participants did not have a urine microalbumin screen. Participant characteristics differed substantially across strata of albuminuria (Table 1). Mean age was significantly higher with increasing albuminuria $(p<$ $0.001)$. Participants with albuminuria ( $>30 \mathrm{mg} / \mathrm{gm}$ ) were more likely to report a personal history of hypertension, diabetes, and kidney disease compared to participants without albuminuria $(p<0.001)$. Albuminuria was also more common among participants who reported a family history of hypertension, diabetes, and kidney disease. Less consistent changes were observed with other sociodemographic characteristics. 


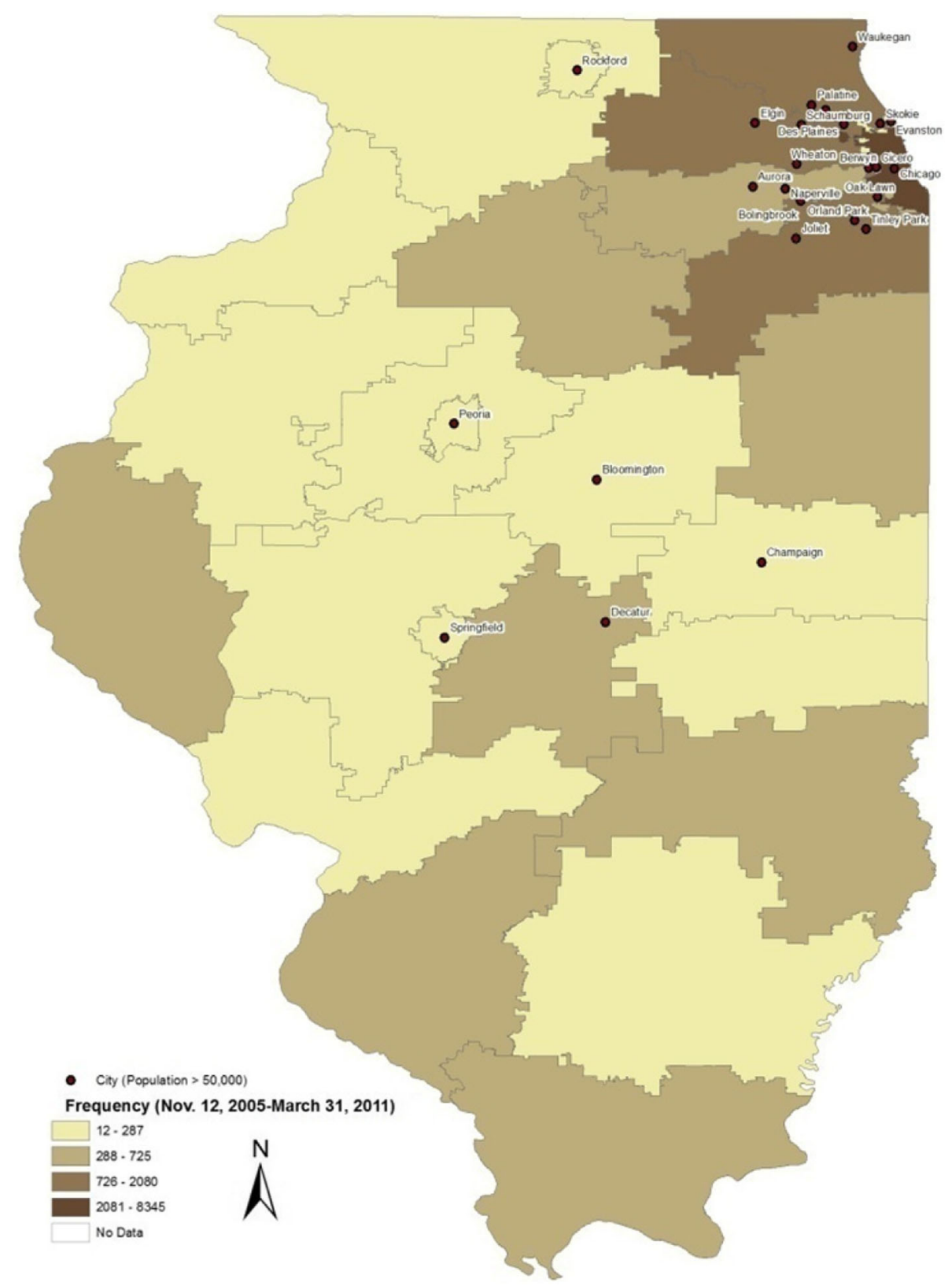

Fig. 1 Distribution of KM screenings across Illinois

Mean systolic and diastolic blood pressure increased significantly with higher albuminuria. The mean systolic blood pressure for participants without albuminuria was $126.3 \mathrm{mmHg}, 130.8 \mathrm{mmHg}$ for those with $30-300 \mathrm{mg} / \mathrm{gm}$ albuminuria, and $143.3 \mathrm{mmHg}$ for those with $>300 \mathrm{mg} / \mathrm{gm}$ albuminuria ( $p$-value $<0.001)$. Diastolic blood pressure also increased with higher albuminuria: $76.1 \mathrm{mmHg}$ in participants without albuminuria, $77.8 \mathrm{mmHg}$ among those with 30-300 $\mathrm{mg} / \mathrm{gm}$ of albuminuria, and $80.4 \mathrm{mmHg}$ among those with $>300 \mathrm{mg} / \mathrm{gm}$ of albuminuria $(p$-value $<0.001)$.

Increasing albuminuria was associated with poorer blood glucose control. Four percent of participants without albuminuria had a fasting blood glucose of $>126 \mathrm{mg} / \mathrm{dl}$ or a non-fasting glucose $>200$, whereas $10 \%$ of participants with $30-300 \mathrm{mg} / \mathrm{gm}$ and $22 \%$ of those with $>300 \mathrm{mg} / \mathrm{gm}$ of albuminuria had abnormal blood glucose levels.

Estimated glomerular filtration rate among a subgroup of patients with abnormal screening results

A total of 4014 participants with albuminuria and either hypertension or diabetes underwent serum blood testing and calculation of eGFR (Table 2). There was a significant association between albuminuria and eGFR $(p<0.001)$. 


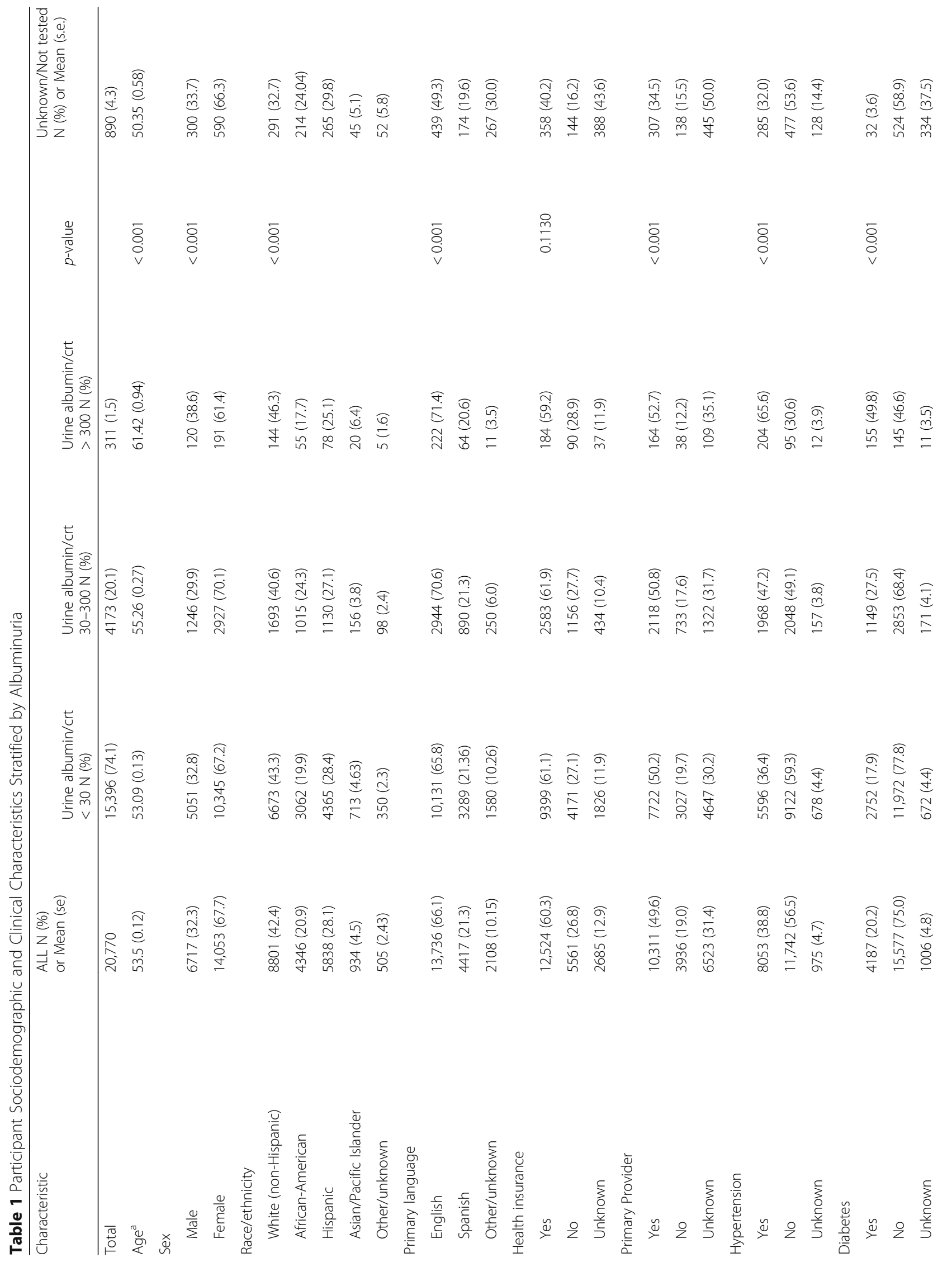




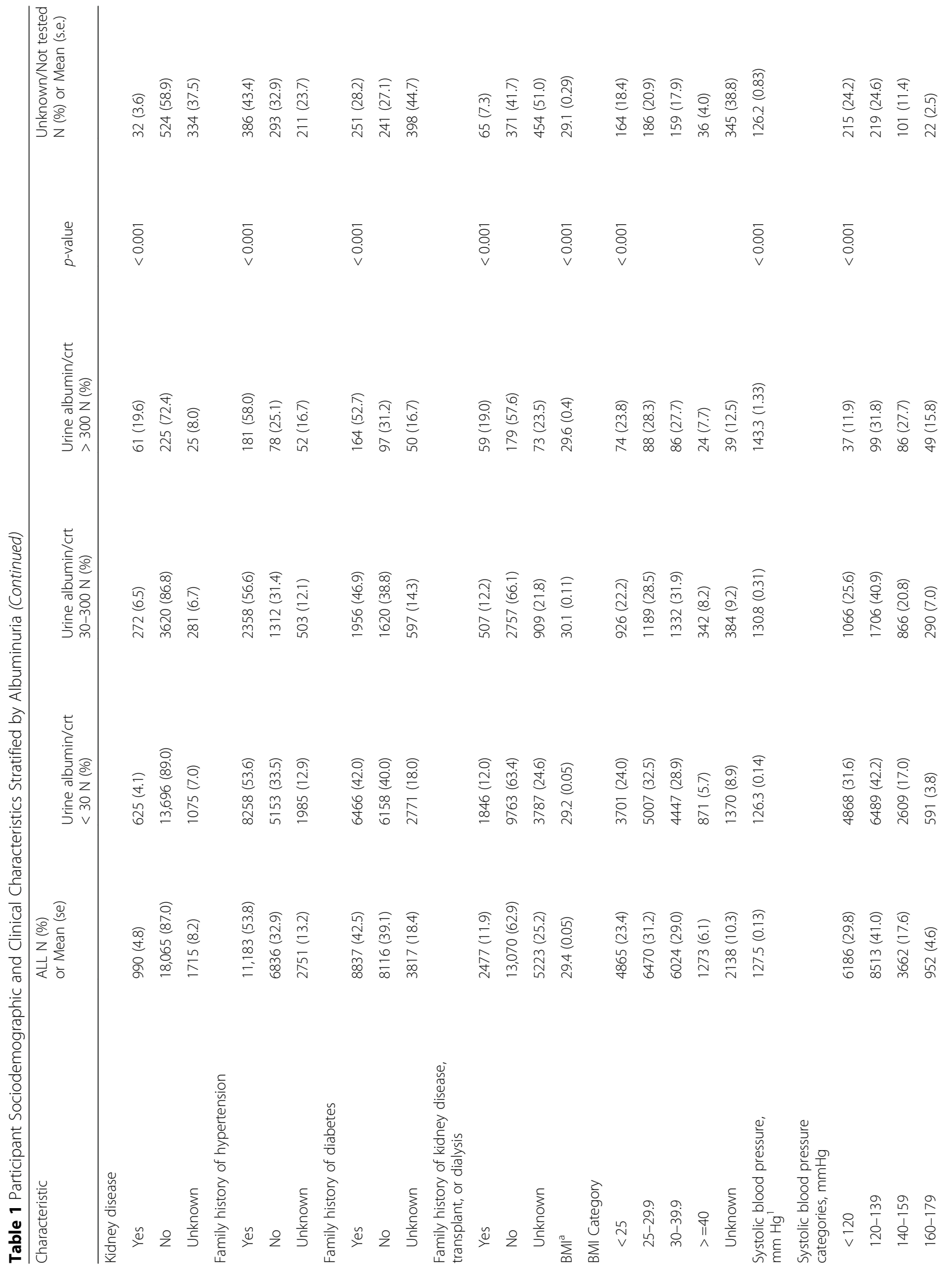




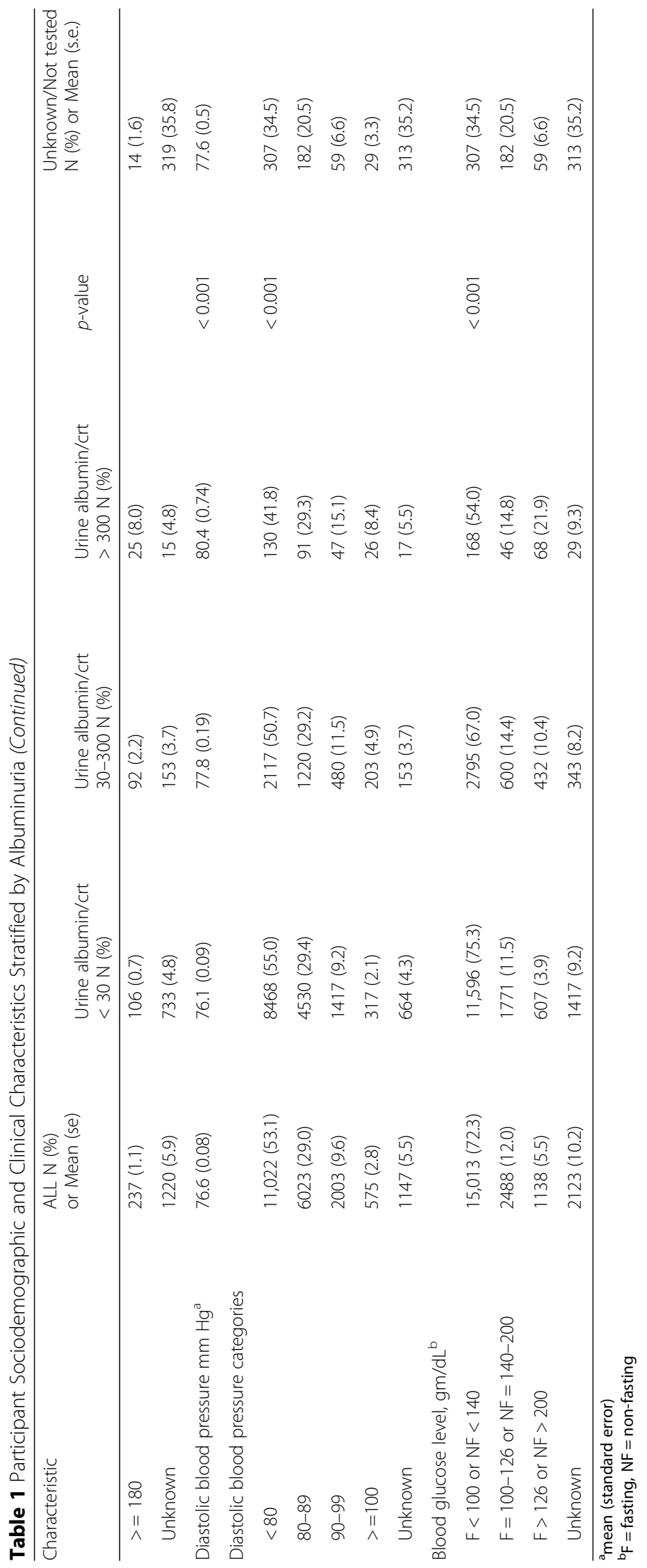


Table 2 Estimated GFR among a subgroup of 4014 participants with abnormal lab results

\begin{tabular}{|c|c|c|c|c|c|c|}
\hline & $\begin{array}{l}\text { ALL N (\%) or } \\
\text { Mean (se) }\end{array}$ & $\begin{array}{l}\text { Urine albumin/crt } \\
<30 \mathrm{~N}(\%)\end{array}$ & $\begin{array}{l}\text { Urine albumin/crt } \\
\text { 30-300 N (\%) }\end{array}$ & $\begin{array}{l}\text { Urine albumin/crt } \\
>300 \mathrm{~N}(\%)\end{array}$ & $p$-value & $\begin{array}{l}\text { Unknown/Not tested } \\
N(\%) \text { or Mean (s.e.) }\end{array}$ \\
\hline Total & 4014 & 2873 & 982 & 311 & & 70 \\
\hline \multicolumn{7}{|c|}{ eGFR, $\mathrm{ml} / \mathrm{min} / 1.73 \mathrm{~m}^{2}$} \\
\hline$>=60$ & $3203(79.8)$ & $2427(84.5)$ & $692(70.5)$ & $36(40.4)$ & \multirow[t]{3}{*}{$<0.001$} & 48 \\
\hline $30-59$ & $723(18.0)$ & $414(14.4)$ & $252(25.7)$ & $36(40.4)$ & & 21 \\
\hline$<=29$ & $88(2.2)$ & $32(1.1)$ & $38(3.9)$ & $17(19.1)$ & & 1 \\
\hline
\end{tabular}

Among participants without albuminuria, most (85\%) had an eGFR > $=60 \mathrm{ml} / \mathrm{min} / 1.73 \mathrm{~m}^{2}$, whereas $14 \%$ had an eGFR between 30 and $59 \mathrm{ml} / \mathrm{min} / 1.73 \mathrm{~m}^{2}$ and $1 \%$ had an eGFR $<30 \mathrm{ml} / \mathrm{min} / 1.73 \mathrm{~m}^{2}$. Twenty-six percent of participants with $30-300 \mathrm{mg} / \mathrm{gm}$ of albuminuria and $40 \%$ of those with $>300 \mathrm{mg} / \mathrm{gm}$ of albuminuria had an eGFR between 30 and $59 \mathrm{ml} / \mathrm{min} / 1.73 \mathrm{~m}^{2}$, and almost $20 \%$ of participants with $>300 \mathrm{mg} / \mathrm{gm}$ of albuminuria had an eGFR of $<30 \mathrm{ml} / \mathrm{min} / 1.73 \mathrm{~m}^{2}$.

Prevalence, awareness, and control of diabetes, hypertension, and kidney disease among participants Fifty percent of participants had prevalent hypertension, as defined by self-reported history of hypertension, systolic blood pressure $\geq 140 \mathrm{mmHg}$, or a diastolic blood pressure $\geq 90 \mathrm{mmHg}$. Of those with hypertension, $78 \%$ were aware of a hypertension diagnosis prior to the screening. Among patients with a reported history of hypertension, about half (53\%) were well-controlled with a systolic blood pressure of $<140 \mathrm{mmHg}$ and a diastolic blood pressure of $<90 \mathrm{mmHg}$ (Fig. 2).

Twenty-two percent of study participants had prevalent diabetes, as defined by a self-reported history of diabetes, a fasting blood glucose $>126 \mathrm{mg} / \mathrm{dl}$, or a non-fasting blood glucose of $>200 \mathrm{mg} / \mathrm{dl}$. Among those with diabetes, $93 \%$ reported awareness of diabetes diagnosis prior to the screening. Only $24 \%$ of participants who reported diabetes were well-controlled with a fasting $\mathrm{BS}<130$ or a non-fasting BS < 180 (Fig. 2).
Twenty-seven percent of participants had prevalent CKD, as defined by a reported history of CKD or a urine albumin/creatinine ratio of $\geq 30 \mathrm{mg} / \mathrm{gm}$. Only $19 \%$ of participants with CKD were aware of this diagnosis prior to the screening. (Fig. 2).

\section{Access to healthcare among participants with prevalent hypertension, diabetes, and CKD}

Compared to all participants, access to healthcare was better among participants with hypertension and diabetes and similar among participants with CKD. Approximately $19 \%$ of participants with prevalent hypertension, $21 \%$ of those with diabetes, and $29 \%$ with CKD reported lacking health insurance, whereas approximately $27 \%$ of all participants reported not having health insurance. Eleven percent of participants with hypertension, $10 \%$ with diabetes, and $18 \%$ with CKD, reported not having a primary care provider, while $19 \%$ of all participants reported not having one (Fig. 3).

\section{Post-screening telephone follow up}

A total of 4937 participants with abnormal screening findings (e.g., elevated blood pressure, elevated blood glucose readings, and abnormal urine findings) were reached by telephone for a follow up interview after their screening. Of these participants, 3387 or $68.6 \%$ reported follow up with a healthcare provider, whereas 1138 participants $(23.1 \%)$ reported no follow up. Of the participants who obtained healthcare post-screening,

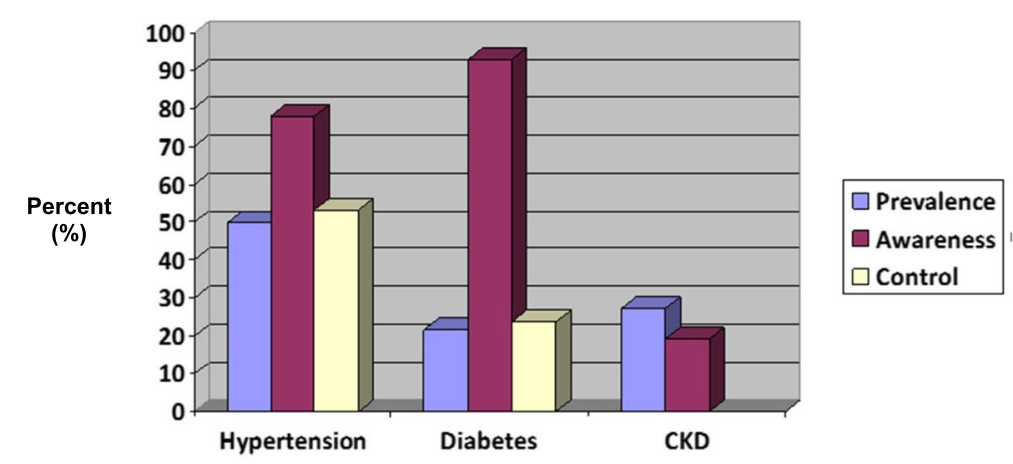

Fig. 2 Prevalence, awareness, and control of hypertension, diabetes, and chronic kidney disease 


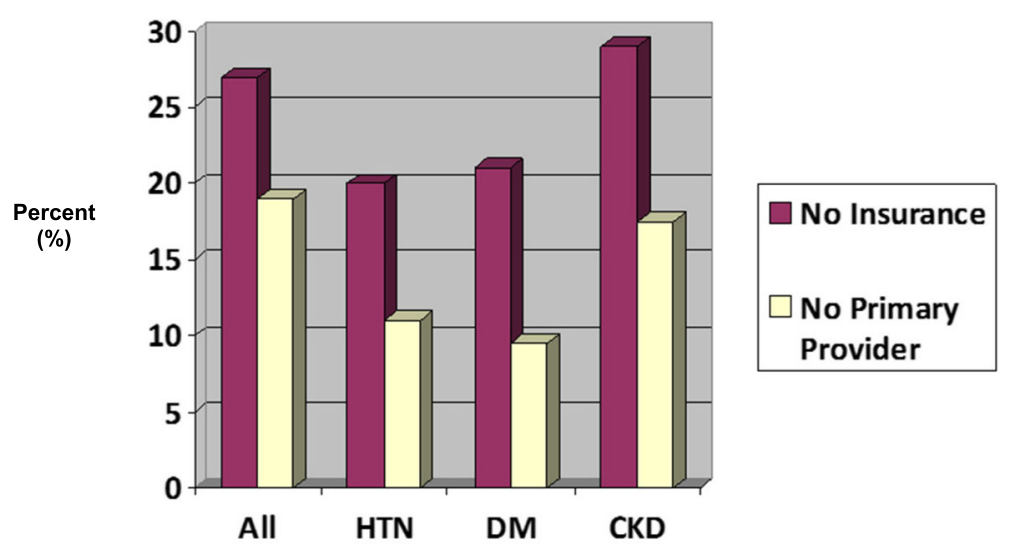

Fig. 3 Lack of health care access among participants with prevalent hypertension, diabetes, and chronic kidney disease

$1580(46.6 \%)$ had repeat testing and 1317 (38.9\%) reported initiation of treatment for their condition.

\section{Discussion}

Among a diverse cohort of 20,770 adults across the state of Illinois who participated in health screenings by the NKFI KM, we found a significant prevalence of undetected and poorly controlled hypertension, diabetes, and kidney disease. At KM screenings, $78 \%$ of adults with prevalent hypertension were aware of their hypertension, $93 \%$ of participants with prevalent diabetes were aware of their diabetes, but only $19 \%$ of participants with prevalent CKD were aware of having the condition. Among those participants reporting hypertension, 53\% had adequate blood pressure control as defined by $\leq 140 / 90 \mathrm{mmHg}$, and in those reporting diabetes, $24 \%$ had adequate control, as defined by a fasting blood glucose $\leq 130 \mathrm{mg} / \mathrm{dl}$ or a non-fasting blood glucose $<180 \mathrm{mg} / \mathrm{dl}$. The NKFI KM reached an underserved population as $27 \%$ of participants reported lacking health insurance and 19\% did not have access to a healthcare provider. The NKFI KM assisted many underserved participants in addressing their healthcare needs. Among five thousand individuals with abnormal findings who participated in a post-screening interview, almost $70 \%$ had a healthcare provider appointment and further evaluation arranged through the NKFI.

Hypertension and diabetes comprise leading causes of CKD, and control of these conditions is needed to prevent CKD and related complications [1, 27, 28]. Studies have shown that adults who are provided with a diagnosis of hypertension and diabetes have better control of these conditions [16], which in turn reduces the incidence of CKD and slower progression of established CKD [27, 29-31]. Similarly, individuals who are made aware of a diagnosis of kidney disease are more likely to obtain CKD care, which may help reduce their incidence of ESKD and CKD related complications [6, 32]. The positive impact of disease awareness on clinical outcomes underscores the importance of timely diagnosis of these conditions. However, it is important to note that there can be unintended results of screening, including unnecessary worry by participants, barriers to securing disability insurance for participants, and generation of additional testing and/or treatments that may not yield better outcomes. While large health screenings for diabetes, hypertension, and kidney disease such as the KEEP study are common, there are fewer examples of mobile health screenings such as the NKFI KM. Mobile health screenings offer specific advantages of being able to reach individuals without health insurance or a primary provider and who have less geographic mobility. In addition, mobile health screenings can target certain geographic areas overrepresented by disadvantaged and high-risk groups [16, 33, 34]. Our mobile screening initiative allowed us to reach a more vulnerable and disadvantaged population (e.g., lack primary provider, lack health insurance, racial/ethnic minority, non-English speaking) than that represented in broader screening initiatives such as NHANES and KEEP [35]. Furthermore, approximately $22 \%$ of $\mathrm{KM}$ participants were found to have albuminuria, which is markedly higher than that identified by KEEP (12\%) or NHANES $(10 \%)[35,36]$.

We found a significant burden of undiagnosed hypertension, diabetes, and kidney disease among NKFI KM participants, consistent with findings from KEEP [37]. The KEEP initiative screened adult patients between the ages of 18-65 years, with either a personal or first-degree family history of diabetes, hypertension and/or chronic kidney disease across the United States. In contrast, the NKFI KidneyMobile screened all adult participants over the age of 18 irrespective of their personal or family health history throughout the state of Illinois. Among participants with abnormal screening results, KEEP investigators found that $35 \%$ of those with elevated blood pressure $(>=140 / 90)$, $2 \%$ with abnormal serum glucose $(>=180), 96 \%$ with 
albuminuria were unaware of a personal history of hypertension, diabetes, and/or kidney disease, respectively [37]. Using a more inclusive screening protocol, we found that $22 \%$ of participants with elevated blood pressure $(>=140 /$ 90), 7\% of participants with elevated blood glucose (Fasting $\geq 126 \mathrm{mg} / \mathrm{dl}$, Non-Fasting $\geq 200 \mathrm{mg} / \mathrm{dl}$ ), and $81 \%$ of participants with albuminuria (>30 mg/gm) were unaware of a personal history of hypertension, diabetes, and kidney disease, respectively.

It is well known that poor control of hypertension and diabetes leads to an increased risk of cardiovascular disease, ESKD, and death [27, 28]. However, control of hypertension and diabetes remains suboptimal per recent reports in representative American samples $[38,39]$. Similar to our findings, other screening studies have also found suboptimal control of hypertension and diabetes among adults who have known disease. In KEEP, $64 \%$ of participants with known hypertension had elevated blood pressure $(>=140 / 90)$ and $35 \%$ of those with known diabetes had an elevated serum glucose level (glucose level $\geq 180 \mathrm{mg} / \mathrm{dl}$ ) [37]. We found that $47 \%$ of participants with known hypertension had an elevated blood pressure $(>=140$ / 90) and $76 \%$ of participants with known diabetes had inadequate control of blood glucose level (fasting $>=$ $130 \mathrm{mg} / \mathrm{dl}$, non-fasting $>=180 \mathrm{mg} / \mathrm{dl}$ ).

While screening studies have assessed the prevalence of undetected and uncontrolled hypertension, diabetes, and kidney disease within high-risk communities $[17,40]$, few have coupled screening with disease education or examined the impact of screenings on participants likelihood to follow-up for further care [37, 40], All KM screenings involved interactive, nurse-led educational sessions pertaining to the prevention, detection, and management of silent chronic diseases (e.g., CKD, hypertension, diabetes, obesity, hyperlipidemia). Furthermore, as part of the NKFI KM mission, all participants were given the opportunity to obtain an on-site consultation with a healthcare professional. Individuals with abnormal anthropomorphic parameters or laboratory data also received assistance with obtaining follow up medical evaluation and treatment postscreening. Based on post-screening phone calls by the NKFI staff, these efforts appeared to be quite successful as many participants reached by phone (77\%) reported having had an appointment with a healthcare provider after the NKFI KM screening, and of those, $47 \%$ reported having undergone repeat testing and 39\% reported initiation of medical treatment. Although the impact of this follow-up care cannot be assessed by our study, it clearly provides an opportunity for intervening and reducing complications from these conditions. A future large study would be helpful to examine whether such screening and follow up endeavors, such as the NKFI KM, affects clinical outcomes.

While our study involved a large diverse participant sample across the state of Illinois and employed detailed data collection strategies with rigorously trained study personnel, it does have limitations. First, like other screening studies such as KEEP and NHANES, only a single anthropomorphic and laboratory measurement for diabetes, hypertension, and kidney disease were done and this does not allow for a diagnosis. Repeated measurements of blood pressure and laboratory tests are generally recommended to support a new diagnosis of hypertension, diabetes, or chronic kidney disease, which underscores the importance of the NKFI KM's coordination of medical follow up for participants with abnormal values. Also, because HbA1C was rarely performed at screening, we relied on capillary blood glucose levels to assess presence and control of diabetes, and these values may vary greatly depending on timing of meals and anti-glycemic agent, and therefore allows for possible misclassification of diabetes prevalence and control [24]. Second, we encountered missing sociodemographic, medical history, and laboratory data that may bias our results. However, missing data occurred rarely and comprised a minority of all data. Third, serum creatinine values were only obtained in participants who had urine studies positive for albumin so we may have missed participants with non-proteinuric kidney disease and underreported the prevalence of kidney disease in this screening cohort. Also, given the mobile nature and time period of the screening initiative, measurement of serum creatinine was not calibrated or standardized in a central laboratory to IDMS, which could introduce error into reported eGFR values. Fourth, as with many screening initiatives, motivational bias may have resulted in individuals participating in more than one free screening and/or attracted individual with existing health concerns, which limits the generalizability of the results.

\section{Conclusion}

In summary, we found a high prevalence of hypertension, diabetes, and kidney disease among participants without known disease as well as poor control of these chronic conditions in participants with known disease. Additionally, the screening and follow up procedures of the NKFI KM appear to be connecting many adults with undiagnosed and uncontrolled conditions to much needed healthcare services. These results reinforce the continued need for mobile disease screening units like the NKFI KM to reach high-risk populations who often lack regular access to healthcare. Additional studies are needed to examine the impact of such mobile screening facilities on important and well-recognized clinical outcomes over time. 


\section{Abbreviations}

CKD: Chronic Kidney Disease; eGFR: Estimated Glomerular Filtration Rate; ESKD: End-Stage Kidney Disease; KM: KidneyMobile; NKFI: National Kidney Foundation of Illinois; VA: United States Department of Veteran Affairs

\section{Acknowledgements}

We thank Anne Black and Mara Lidacis for their administrative support at the NKFI and Weihan Zhao, PhD for his help with statistical analyses. The contents presented in this paper are those of the authors and do not represent the views of the U.S. Department of Veterans Affairs or the United States Government.

\section{Funding}

Funding for data analysis for this study was provided by National Kidney Foundation of Illinois. Additional support was provided from the VA Office of Academic Affiliations, Advance Fellowship Program in Health Services Research (Swati Lederer). Dr. Lash is supported by K24-DK092290.

\section{Availability of data and materials}

Datasets generated and/or analyzed during the current study are not publicly available due to the IRB's regulation, but are available from the corresponding author on reasonable request.

\section{Authors' contributions}

$S L$ : data analyses, drafted manuscript, contributed to critical revision of the manuscript, approved the final version of the manuscript. LR: study design, data analyses, contributed to critical revision of the manuscript, approved the final version of the manuscript. NMS: data collection, contributed to critical revision of the manuscript, approved the final version of the manuscript. $\mathrm{NL}$ : data collection, contributed to critical revision of the manuscript, approved the final version of the manuscript. KGO: data collection, contributed to critical revision of the manuscript, approved the final version of the manuscript. YW: data analyses, contributed to critical revision of the manuscript, approved the final version of the manuscript. JC: data analyses, contributed to critical revision of the manuscript, approved the final version of the manuscript. JPL: data analyses, contributed to critical revision of the manuscript, approved the final version of the manuscript. MJF: study design, data analyses, contributed to critical revision of the manuscript, approved the final version of the manuscript.

\section{Ethics approval and consent to participate}

Participants provided written consent for their participation in the NFK Kidney Mobile and for the release of their data to be used for research analyses. The University of Illinois in Chicago's IRB provided oversight for conducting a retrospective analyses using a de-identified dataset.

\section{Consent for publication}

Not applicable.

\section{Competing interests}

The authors declare that they have no competing interests.

\section{Publisher's Note}

Springer Nature remains neutral with regard to jurisdictional claims in published maps and institutional affiliations.

\footnotetext{
Author details

${ }^{1}$ Center of Innovation for Complex Chronic Healthcare, Jesse Brown VA Medical Center, Chicago, IL, USA. ${ }^{2}$ Edward Hines Jr. VA Hospital, Hines, IL, USA. ${ }^{3}$ Department of Medicine, University of Illinois at Chicago, College of Medicine, Chicago, IL, USA. ${ }^{4}$ Department of Medicine, VA North Texas Healthcare System, 4500 South Lancaster Ave, MC 111G1, Dallas, TX 75216, USA. ${ }^{5}$ National Kidney Foundation of Illinois, Chicago, IL, USA. ${ }^{6}$ Community Health Sciences Division/Institute for Health Research and Policy, School of Public Health, University of Illinois at Chicago, Chicago, IL, USA. ${ }^{7}$ Behavioral Health and Nutrition, College of Health Sciences, University of Delaware, Newark, DE, USA.
}

Received: 6 November 2017 Accepted: 8 October 2018

Published online: 25 October 2018

\section{References}

1. Saran R, Li Y, Robinson B, Ayanian J, Balkrishnan R, Bragg-Gresham J, Chen JT, Cope E, Gipson D, He K, et al. US renal data system 2014 annual data report: epidemiology of kidney disease in the United States. Am J Kidney Dis. 2015:65(6 Suppl 1):A7.

2. Go AS, Chertow GM, Fan D, McCulloch CE, Hsu CY. Chronic kidney disease and the risks of death, cardiovascular events, and hospitalization. N Engl J Med. 2004;351(13):1296-305.

3. Nickolas TL, Frisch GD, Opotowsky AR, Arons R, Radhakrishnan J. Awareness of kidney disease in the US population: findings from the National Health and nutrition examination survey (NHANES) 1999 to 2000. Am J Kidney Dis. 2004:44(2):185-97.

4. Whaley-Connell A, Shlipak MG, Inker LA, Kurella Tamura M, Bomback AS, Saab G, Szpunar SM, McFarlane SI, Li S, Chen SC, et al. Awareness of kidney disease and relationship to end-stage renal disease and mortality. Am J Med. 2012;125(7):661-9.

5. Vassalotti JA, Li S, McCullough PA, Bakris GL. Kidney early evaluation program: a community-based screening approach to address disparities in chronic kidney disease. Semin Nephrol. 2010;30(1):66-73.

6. Tuot DS, Plantinga LC, Hsu CY, Jordan R, Burrows NR, Hedgeman E, Yee J, Saran R, Powe NR, Centers for Disease Control Chronic Kidney Disease Surveillance T. Chronic kidney disease awareness among individuals with clinical markers of kidney dysfunction. Clin J Am Soc Nephrol. 2011;6(8):1838-44.

7. National Kidney F. K/DOQI clinical practice guidelines for chronic kidney disease: evaluation, classification, and stratification. Am J Kidney Dis. 2002; 39(2 Suppl 1):S1-266.

8. Martínez-Ramírez HR, Cortés-Sanabria L, Rojas-Campos E, Hernández-Herrera A, Cueto-Manzano AM. Multidisciplinary strategies in the management of early chronic kidney disease. Arch Med Res. 2013;44(8):611-5.

9. Nwankwo T, Yoon SS, Burt V, Gu Q. Hypertension among adults in the United States: National Health and nutrition examination survey. NCHS Data Brief. 2011-2012;2013(133):1-8.

10. National Diabetes Statistics Report: Estimate of Diabetes and its Burden in the United States. Atlanta, GA. Center for Disease Control and Prevention, US Department of Health and Human Services. 2015.

11. Crews DC, Pfaff T, Powe NR. Socioeconomic factors and racial disparities in kidney disease outcomes. Semin Nephrol. 2013;33(5):468-75.

12. Palmer Alves T, Lewis J. Racial differences in chronic kidney disease (CKD) and end-stage renal disease (ESRD) in the United States: a social and economic dilemma. Clin Nephrol. 2010;74(Suppl 1):S72-7.

13. Perneger TV, Whelton PK, Klag MJ. Race and end-stage renal disease. Socioeconomic status and access to health care as mediating factors. Arch Intern Med. 1995;155(11):1201-8.

14. Nzerue CM, Demissochew H, Tucker JK. Race and kidney disease: role of social and environmental factors. J Natl Med Assoc. 2002;94(8 Suppl):28S-38S.

15. McCullough PA, Brown WW, Gannon MR, Vassalotti JA, Collins AJ, Chen SC, Bakris GL, Whaley-Connell AT. Sustainable community-based CKD screening methods employed by the National Kidney Foundation's kidney early evaluation program (KEEP). Am J Kidney Dis. 2011;57(3 Suppl 2):S4-8.

16. Victor RG, Ravenell JE, Freeman A, Leonard D, Bhat DG, Shafiq M, Knowles P, Storm JS, Adhikari E, Bibbins-Domingo K, et al. Effectiveness of a barber-based intervention for improving hypertension control in black men: the BARBER-1 study: a cluster randomized trial. Arch Intern Med. 2011;171(4):342-50.

17. Abdelsatir S, Al-Sofi A, Elamin S, Abu-Aisha H. The potential role of nursing students in the implementation of community-based hypertension screening programs in Sudan. Arab J Nephrol Transplant. 2013;6(1):51-4.

18. Santoyo-Olsson J, Cabrera J, Freyre R, Grossman M, Alvarez N, Mathur D, Guerrero M, Delgadillo AT, Kanaya AM, Stewart AL. An innovative multiphased strategy to recruit underserved adults into a randomized trial of a community-based diabetes risk reduction program. Gerontologist. 2011; 51(Suppl 1):S82-93.

19. Aitaoto N, Braun KL, Estrella J, Epeluk A, Tsark J. Design and results of a culturally tailored cancer outreach project by and for Micronesian women. Prev Chronic Dis. 2012;9:E82.

20. Chobanian AV, Bakris GL, Black HR, Cushman WC, Green LA, Izzo JL, Jones DW, Materson BJ, Oparil S, Wright JT, et al. Seventh report of the joint National Committee on prevention, detection, evaluation, and treatment of high blood pressure. Hypertension. 2003;42(6):1206-52. 
21. OneTouch Ultra 2 [http://www.onetouch.com/onetouch-ultra2]. Accessed 10 Oct 2018.

22. Point of Care Testing [http://usa.healthcare.siemens.com/point-of-care]. Accessed 10 Oct 2018

23. Abbott Point of Care [https://www.abbottpointofcare.com/productsservices/istat-handheld]. Accessed 10 Oct 2018

24. American Diabetes A. Standards of medical care in diabetes-2014. Diabetes Care. 2014;37(Suppl 1):S14-80.

25. Group KDIGOKCW. KDIGO 2012 clinical practice guideline for the evaluation and Management of Chronic Kidney Disease. Kidney Int. 2013;3:1-150.

26. Levey AS, Coresh J, Greene T, Stevens LA, Zhang YL, Hendriksen S, Kusek JW, Van Lente F, Chronic Kidney Disease Epidemiology C. Using standardized serum creatinine values in the modification of diet in renal disease study equation for estimating glomerular filtration rate. Ann Intern Med. 2006;145(4):247-54

27. Hemmingsen B, Lund SS, Gluud C, Vaag A, Almdal TP, Hemmingsen C, Wetterslev J. Targeting intensive glycaemic control versus targeting conventional glycaemic control for type 2 diabetes mellitus. Cochrane Database Syst Rev. 2013;11:CD008143.

28. Bakris GL, Ritz E. The message for world kidney day 2009: hypertension and kidney disease: a marriage that should be prevented. Kidney Int. 2009;75(5):449-52.

29. Hsu CY, McCulloch CE, Darbinian J, Go AS, Iribarren C. Elevated blood pressure and risk of end-stage renal disease in subjects without baseline kidney disease. Arch Intern Med. 2005;165(8):923-8.

30. Ohkubo Y, Kishikawa H, Araki E, Miyata T, Isami S, Motoyoshi S, Kojima Y, Furuyoshi N, Shichiri M. Intensive insulin therapy prevents the progression of diabetic microvascular complications in Japanese patients with noninsulin-dependent diabetes mellitus: a randomized prospective 6-year study. Diabetes Res Clin Pract. 1995;28(2):103-17.

31. Coresh J, Wei GL, McQuillan G, Brancati FL, Levey AS, Jones C, Klag MJ. Prevalence of high blood pressure and elevated serum creatinine level in the United States: findings from the third National Health and nutrition examination survey (1988-1994). Arch Intern Med. 2001;161(9):1207-16.

32. Wouters OJ, O'Donoghue DJ, Ritchie J, Kanavos PG, Narva AS. Early chronic kidney disease: diagnosis, management and models of care. Nat Rev Nephrol. 2015;11(8):491-502.

33. Willis J, Lloyd L, Jenkins $W$. Undergraduate students trained to provide basic health care screening in an underserved community: a door-to-door campaign. Work. 2012;41(3):277-84.

34. Saffar D, Perkins DW, Williams V, Kapke A, Mahan M, Milberger S, Brady M, Wisdom K. Screening for diabetes in an African American community: identifying characteristics associated with abnormal blood glucose readings. J Natl Med Assoc. 2011;103(3):190-3.

35. Agrawal V, Jaar BG, Frisby XY, Chen SC, Qiu Y, Li S, Whaley-Connell AT, McCullough PA, Bomback AS, Investigators K. Access to health care among adults evaluated for CKD: findings from the kidney early evaluation program (KEEP). Am J Kidney Dis. 2012;59(3 Suppl 2):S5-15.

36. Chronic Kidney Disease Surveillance System—United States. [http://www. cdc.gov/ckd ]. Accessed 10 Oct 2018.

37. Brown WW, Peters RM, Ohmit SE, Keane WF, Collins A, Chen SC, King K, Klag MJ, Molony DA, Flack JM. Early detection of kidney disease in community settings: the kidney early evaluation program (KEEP). Am J Kidney Dis. 2003; 42(1):22-35

38. Ong KL, Cheung BM, Man YB, Lau CP, Lam KS. Prevalence, awareness, treatment, and control of hypertension among United States adults 19992004. Hypertension. 2007:49(1):69-75.

39. Ong KL, Cheung BM, Wong LY, Wat NM, Tan KC, Lam KS. Prevalence, treatment, and control of diagnosed diabetes in the U.S. National Health and nutrition examination survey 1999-2004. Ann Epidemiol. 2008;18(3):222-9.

40. Wee LE, Koh GC, Yeo WX, Chin RT, Wong J, Seow B. Screening for cardiovascular disease risk factors in an urban low-income setting at baseline and post intervention: a prospective intervention study. Eur J Prev Cardiol. 2013;20(1):176-88.

Ready to submit your research? Choose BMC and benefit from:

- fast, convenient online submission

- thorough peer review by experienced researchers in your field

- rapid publication on acceptance

- support for research data, including large and complex data types

- gold Open Access which fosters wider collaboration and increased citations

- maximum visibility for your research: over $100 \mathrm{M}$ website views per year

At BMC, research is always in progress.

Learn more biomedcentral.com/submissions 